\title{
Supporting Educators in the Design of Constructionist Learning Environment Scenarios: a Framework
}

\author{
Flavio Nicastro ${ }^{1}$, Maria Cecília Calani Baranauskas ${ }^{1}$, Ricardo da Silva Torres ${ }^{1}$ \\ ${ }^{1}$ Institute of Computing, University of Campinas (UNICAMP) \\ Cidade Universitária Zeferino Vaz - 13.083-970, Campinas - SP - Brazil \\ \{flavio.nicastro, cecilia, rtorres\}eic.unicamp.br
}

\begin{abstract}
The adoption of Hands-On/Heads-In activities associated with computational thinking $(C T)$ development has received considerable attention in academic discussions. While the subject of CT is not new, the proposal of environments to support educators in the design and conduction of activities in educational contexts are hardly discussed in the mainstream literature. Handson/Heads-In activities are an essential aspect of Constructionism, proposed by Seymour Papert in the 80's and still worked on by his colleagues and followers in different types of practices. In this work, we contribute with the proposal of a framework to support the design of educational practices based on the principles of Constructionism and Creative Learning, in which Hands-On/Heads-In activities underlie the use of technology.
\end{abstract}

\section{Introduction}

The main ideas behind Constructionism, coined by Seymour Papert, come from "learning by doing." He advocated that construction of knowledge happens in a more efficient way in a context where the learner is consciously involved in the construction of a public thing, no matter whether it is a sand castle or a theory of the universe [Papert and Harel 1991]. One way of achieving construction of knowledge as proposed by Papert, is through Hands-On activities and programming computers. Although Hands-On activities are becoming more and more present in educational contexts [Resnick and Rosenbaum 2013], the proposal of environments to support educators in the the creation and conduction of activities is hardly discussed in the mainstream literature. Consequently, the educators who wish to adopt the principles of constructionism and creative learning rarely find tools that support them.

Bearing this scenario in mind, in this work we introduce a framework (Figure 1 (left)) to assist educators in the design of educational scenarios based on the principles of constructionism and creative learning. This framework enables the educator to design environments with Hands-On/Heads-In activities, using tangible technology artifacts and programming tasks. This approach is intended not only to favor knowledge construction in a more meaningful way [Papert 1980], but also to foster the development of creativity, student protagonism, teamwork, and skills associated with computational thinking [Papert 1993, Resnick and Robinson 2017].

With the goal of analyzing the perceptions of educators and children during an activity based on the proposed framework, we carried out four workshops with six educators and fifteen 8 to 11 years old children in an educational space that offers complementary education to children. At first, the educators were not confident in their capability of designing an activity based on something new as the proposed technology. Our 

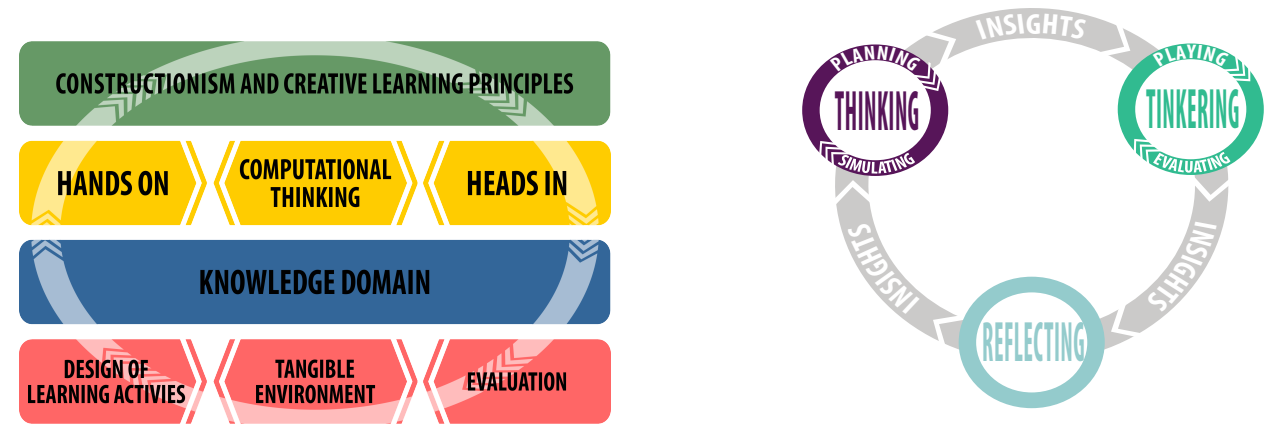

Figure 1. Proposed Framework (Left); and the Three Moments Workflow (Right).

findings show that the use of the framework helped them in gaining confidence on their potential of designing an activity based on the technology, thus revealing that the proposed framework facilitated also their approach to it. At the end of the workshops the educators' and children's affective states were assessed using SAM - Self-Assessment Manikin [Bradley and Lang 1994], showing that both educators and children felt very motivated to carry out the activity based on the proposed framework.

\section{The Proposed Framework and Its Bases}

In this work, we introduce a framework (Figure 1 (left)) for designing educational practices based on technology, constructionism principles, and creative learning. It should foster the construction of a learning scenario based on tangible technology artifacts, to support hands-on practices, and encourage reflection, the development of abilities associated with computational thinking, creativity, teamwork, and child's protagonism. In the following, we describe the elements of the proposed framework.

\subsection{Constructionism and Creative Learning Principles}

Constructionism was inspired by the bases of learning shown in Piaget's Constructivism, which understands learning as "building knowledge structures" regardless of the learning circumstances. Papert adds to this by saying that learning happens most efficiently when students are consciously involved in the construction of tangible artifacts in the real world [Papert and Harel 1991]. Constructionism is knowledge construction based on the realization of a concrete action, which results in a tangible product that concerns the person who constructs it.

Based on Papert's constructionism, Mitchel Resnick proposed the creative learning approach [Resnick and Robinson 2017] to consider technology in education. As stated by Resnick, learning occurs through a creative process when one creates something that is meaningful to them by playing, in collaboration with peers, thus allowing them to grow as creative thinkers. This idea came from the kindergarten approach, where kids have the freedom to express themselves and try out many appealing materials, and, through this process, achieve self development. He argues that the rest of school, or even the rest of life, should be more like a kindergarten, which is the contrary of what is seen today; kindergarten is becoming more like the rest of schooling.

Creative learning is based on four pillars, presented as "The Four P's" by Mitchel Resnick: Projects: give children the opportunity to work on projects, which start with 
VIII Congresso Brasileiro de Informática na Educação (CBIE 2019)

Anais do XXV Workshop de Informática na Escola (WIE 2019)

a vague idea that can turn into a final product; Passion: encourage children to follow their passion, to work with things they really care about. This way they engage more and persist when coming across obstacles in the way; Peers: encourage working with peers and sharing progress, achievements, and challenges. Learning is a social process and not only a personal achievement; Play: provide a playful approach for learning, a scenario in which children are constantly experimenting, taking risks, and trying new things. Complementing this approach, Resnick presents the spiral of creative learning ([Resnick and Robinson 2017], p.11), showing the learning process as a continuous endeavor. As part of an initial idea (imagine), something is created (create). Next, the idea is played with, by trying out several ways of thinking (play). The creation is then shared with peers, and feedback is given and received (share). After this, the whole process is reflected upon (reflect), and through this reflection, new ideas come up (imagine) and the process starts again, continuously.

\subsection{Hands-On}

Hands-On can be understood as "getting involved in building something." It does not necessarily have to do with a physical object (a chair, for example); it could be something tangible (digital, conceptual) that has shape and meaning, such as a chair, but also a poem, a song, a computer program, or even, a way of thinking. In this regard, HandsOn fits in perfectly with constructionism because it is exactly what Papert argues: when getting involved in building something significant, learning happens. Thus, Hands-On is understood as a means to reach the construction of knowledge, according to the bases of constructionism. Papert advocates the need to learn through creative processes, as well as discovering knowledge rather than receiving it passively. Hands-On provides this different perspective in the learning process, giving learners the opportunity to have control over their own knowledge, rather than being passive receivers.

\subsection{Heads-In}

Not only does Hands-On favor learning, but also the process of reflection that it provides is of huge importance for the construction of knowledge. Seymour Papert [Papert 1980], Edith K. Ackermann [Ackermann 1995], and Mitchel Resnick [Resnick and Robinson 2017] clearly bring this concept into their works. Edith reveals that Hands-On activities remain essentially undirected and non-controllable, blind, and meaningless, when not fully reflected upon. In line with Edith's work, Heads-In requires us to evaluate what we have done in light of what we would like to achieve. The inclusion of Heads-In in our framework means that the scenario to be designed needs to provide means for reflection, when students are expected to analyze what they have done, the results achieved, the strategies used, and the paths followed.

\subsection{Computational Thinking}

Computational thinking is not a new concept. In the 1970s, Seymour Papert was a pioneer with the LOGO language and studies concerning the learning processes of children mediated by the use of programming language and other technology artifacts. Those artifacts include a turtle robot that helped to understand concepts of geometry through anthropomorphism and programming in the LOGO language [Papert 1980]. Since then, several works have been done on computational thinking and educational robotics. In 
VIII Congresso Brasileiro de Informática na Educação (CBIE 2019)

Anais do XXV Workshop de Informática na Escola (WIE 2019)

2006, Jeannette Wing's publication, “Computational Thinking” [Wing 2006], had a huge impact, bringing popularity and raising again the interest of academics to the subject of computational thinking (CT). In her work, Jeannette Wing presents CT as a set of problem-solving mental process derived from Computer Science, applicable to any domain. She introduces the idea that $\mathrm{CT}$ is a main practice for all sciences. She also states that CT is a fundamental and useful analytical thinking skill for everyone.

Regardless of the numerous definitions that have already been proposed for the computational thinking term, and the discussion raised, it is possible to acknowledge that activities which aim at the development of skills associated with computational thinking are benefited from practices both Hands-On and Heads-In. Within CT mindset, HandsOn activities are related to the construction of a computer program in which the person will be involved in the whole process of building this program, from its initial design to its numerous versions that may be developed. Heads-In happens, because in order to have the program executing as expected, it is necessary to think of all the commands necessary for the desired actions. Besides this, it is necessary to analyze the result of execution, compare it with what was intended, find inconsistencies and ways to solve them. In addition to these points, with the development of computer programs, it is possible to debug it. This consists of reviewing step by step the execution of what was anticipated / programmed in order to find / analyze where the bug is and, consequently, allowing developers to become aware of what they are doing wrong and reflect on new ways of addressing the target problem. This is possibly unique in the process of creating programs, when compared to the design of other artefacts, which makes activities aimed at the development of skills associated with computational thinking quite powerful.

\subsection{Knowledge Domain}

We understand that the whole process described here will be useful when applied to the contents or knowledge domains that are expected to be addressed in schools. For this reason, one of the elements of our framework is "Knowledge Domain." It relates to any kind of knowledge, skills, or competencies that one wishes to develop. A Hands-On / Heads-In activity that develops skills associated with computational thinking, based on the principles of constructionism and creative learning, should allow the work on the desired contents to become more meaningful and manipulable. For example, a project involving geography and biology classes in which students would research and show how a virus spreads over the world, could involve the creation of a program connected to a model made with recyclable material.

\subsection{Design of Learning Activities}

In a learning environment, the educator should take all the elements of the framework into account and define ways in which each one would be addressed. In order to assist educators in this task, we propose a workflow with three moments: thinking, tinkering, and reflecting. The section 2.9 explores the workflow in more detail.

\subsection{Tangible Environment}

The idea of using tangible interaction to build computer programs began in the 1970s with the creation of physical programs for the Logo language. In his 1980 Mindstorms book [Papert 1980], Seymour Papert already advocated the idea that children learn when 
VIII Congresso Brasileiro de Informática na Educação (CBIE 2019)

Anais do XXV Workshop de Informática na Escola (WIE 2019)

they manipulate objects. One way of exploring activities based on constructionism principles is through the use of "Tangible User Interfaces" (TUIs) - user interfaces employing physical objects, instruments, surfaces, and spaces; varying from physical interfaces to digital information. TUIs augment the real physical world by joining digital information with everyday physical objects and environments [Ishii and Ullmer 1997]. Studies show that tangible interfaces can promote greater engagement with high potential of involving children and improving the learning of complex concepts. Also, the development of children's cognitive and socio-emotional skills is favored by coding, besides promoting collaboration and helping teachers maintain a positive atmosphere in the learning environment. Another relevant point in favor of tangible interfaces is the fact that synesthesia is very important for younger children while learning because they learn by touching, looking, hearing, and smelling [Horn et al. 2009, Zuckerman et al. 2005, Liao and Bright 1991].

\subsection{Evaluation}

Last but not least, it is important to define how the learning environment scenario will be assessed. Which items will be evaluated and how? Which evaluation dimensions to use: development of skills associated with computational thinking, development of creativity, protagonism, and teamwork of the learners and, in general, evaluation of the effectiveness of the designed environment. While assessing, it should be taken into consideration whether these points are being promoted by the technology in the designed environment.

\subsection{A Workflow for Designing Educational Practices}

To guide the design of an educational environment, complying with the introduced framework, we propose a workflow (Figure 1 (right)) with key steps that are detailed as follows. This workflow is composed of three moments: Thinking, Tinkering, and Reflecting. This workflow can be used to assist the educator in the designing phase of a learning environment scenario and also during the conduction of activities with children.

During the thinking moment, the educator plans and simulates an activity to be done within the desired environment. The planning consists of defining the goals of the activity and steps to achieve them. Also, the planner should consider: skills intended to be developed, tangible artifacts to support the activity, programming tasks, timeframe, and tools to evaluate the results. Besides this, the bases of Creative Learning should not be forgotten: Projects, Passion, Peers, and Play as mentioned in Section 2.1. Simulation consists of assessing the planning, to verify whether the defined steps lead to the goals and whether the timeframe is according to what was planned. Planning and simulation can occur at the same time or not; it is important to care about the effectiveness of the planning.

During the Tinkering moment, educators conduct the activity with their students, evaluating it with the defined tools. Tinkering is characterized by a playful, exploratory, and iterative style of engaging with a problem or project. When people are tinkering, they are constantly trying out ideas, making adjustments and refining, then experimenting with new possibilities [Resnick and Rosenbaum 2013]. For this reason, the educator should be an active agent when conducting an activity, evaluating the progress, suggesting strategies, and fostering the three moments: thinking, tinkering, and reflecting. 
During the reflection moment, the educator should analyze the observations made during the workshop, using, for example, the results of the instruments utilized to assess the activity (e.g., forms filled out by the students). While doing so, they should reflect on whether the goals have been reached satisfactorily and how the new insights could improve their workshops.

This workflow is also important to be used by the children during the activity. For this, the educator should promote the three moments with students. In the thinking moment, the students think about the ideas and manners to approach a proposed challenge. Tinkering moment, is when the students put their ideas into practice, trying and experimenting diverse solutions for the problem. Finally, during the reflection moment, they will reflect on the results, the challenges faced and the ways used to overcome them. These three moments can occur at the same time, with the students thinking, tinkering, and reflecting upon a challenge. Children should be free when performing the activity, i.e., they are not stuck in a strict process or following a "cake recipe." However, they should be encouraged to engage in the development of solutions and think about what they are doing, and how. They should reflect on what results they are achieving and on the strategies used to address/solve the problems, instead of only doing the activity on a trial-and-error basis.

In the following section, we present four workshops in which we used this workflow to design activities with educators and to guide the development of learning activities with children.

\section{Case Study}

In order to put the proposed framework into practice, we conducted two workshops with educators and two other workshops with their students at an educational space that provides children with complementary education. The workshops involved six educators and fifteen 8 to 11 years old children.

\subsection{Experimental Protocol for the Workshops}

The workshops involving the educators consisted of designing a learning environment scenario based in a proposed technology and the proposed framework; this scenario would later be used within the children's workshops. The goal was to plan an activity related to a theme that they were working on in their classes. Moreover, the activity aimed at developing skills associated with computational thinking, more specifically, introducing the concept of algorithms by solving a programming task. Initially, we talked about the bases of constructionism and creative learning with the educators. Following this, we discussed the framework and the workflow that would guide the activities. Also, we presented Cubetto ${ }^{1}$ as a tangible artifact that could be used. We explained how it works and provided an overview about possible commands to be used. Cubetto is a wooden robot which can be used with the purpose of teaching children basic computer programming concepts. It is programmed with a programming board in which instruction blocks fit in. The children combine blocks to create programs. Possible instructions are: move forward, turn left, and turn right. Furthermore, it includes the possibility of implementing the concept of procedure by using a special block. Coding blocks are easily used by children,

\footnotetext{
${ }^{1}$ https : / / www . primotoys. com/ (As of Jan. 2019).
} 
VIII Congresso Brasileiro de Informática na Educação (CBIE 2019)

Anais do XXV Workshop de Informática na Escola (WIE 2019)

regardless of their reading abilities and language barriers. We then asked the educators to think about an activity to be conducted with the children. During the Thinking Moment, the educators discussed the possibilities of different learning designs and tried out some ideas of tasks involving the wooden robot. They spent about 1 hour with this process, planning and simulating their ideas. At the end of this phase, they registered the activity plan on a form that we supplied them with and moved on to the Tinkering Moment.

Once the Tinkering Moment started, the activity was conducted with the children. The goals of the activity were explained to the children and the wooden robot was presented to them, along with usage possibilities. Our orientation was that the activity should follow the three moments of the workflow. During the first moment, the children were asked to think about the activity and, plan and simulate possible solutions. After that, they tried out their plan with the wooden robot, evaluating the goals, and correcting mistakes. In order to foster reflection, they were asked to discuss the activity with their classmates about and new ideas that they could implement in order to improve the results.

After conducting the activity with the children, the educators were asked to reflect on the results and discuss what went well, what could have been (can be) improved, and which mistakes were done. This reflection, along with the observations made by the educators during the activity, and the analysis of the notes taken by the children should be used as inputs for future insights. At the end of each activity, all participants (educators and children) filled out a Self-Assessment Manikin (SAM) instrument [Bradley and Lang 1994]. SAM is a nonverbal instrument of self-assessment of emotions, specifically measuring the pleasure, arousal, and dominance associated with a person's affective reaction to a wide variety of stimuli. According to the authors, through these tree dimensions, it is possible to describe any emotion. SAM consists of a pictographic representation where one can register their level of affective state in each dimension. This representation allows the questionnaire to be answered by people who have difficulties with written information. Furthermore, it minimizes bias caused by different interpretations of words used to describe affective states. For each of the three dimensions of valence presented by SAM, the scale of responses range from 1 to 9 , in which 1 represents the lowest level (of pleasure, arousal, or dominance) and 9 represents the highest level. Additionally, the students answered a short questionnaire regarding their perceptions of the workshops.

This protocol ensures that the design is in accordance with the proposed framework and with the three moments of our workflow. Table 1 shows how each element of the framework was covered during the design of the activity, while Table 2 shows how the three moments were handled by the participants.

\subsection{Results and Discussion}

Overall, the workshops were well appreciated by both educators and children. In the beginning, the educators were not confident in their ability to design an activity on something that they did not know in advance (technology, programming). However, after starting, they became excited, and the activities were performed enthusiastically. During the thinking moment of the children, all groups were quite entertained and developed their solution to solve the tasks. After receiving the wooden robot, they coded programs following what they had planned. When their execution did not reach the goal, they stayed 
VIII Congresso Brasileiro de Informática na Educação (CBIE 2019)

Anais do XXV Workshop de Informática na Escola (WIE 2019)

Table 1. Analysis of how each element of the proposed framework was covered in the designed learning environment.

\begin{tabular}{|c|c|}
\hline Framework element & How was it covered? \\
\hline Hands-On & $\begin{array}{l}\text { By the engagement of students in an activity, drawing possible } \\
\text { solutions and tinkering with a wooden robot and its compo- } \\
\text { nents, in order to solve the proposed challenge. }\end{array}$ \\
\hline Computational Thinking & $\begin{array}{l}\text { By developing the concept of algorithms through tangible pro- } \\
\text { gramming. }\end{array}$ \\
\hline Heads-In & $\begin{array}{l}\text { By the children's discussions on how to solve the challenge, } \\
\text { the reflections on solutions and difficulties faced throughout } \\
\text { the activity, besides the sharing of ideas with classmates. }\end{array}$ \\
\hline Knowledge Domain & By working on storytelling. \\
\hline $\begin{array}{l}\text { Design of Learning Activ- } \\
\text { ities }\end{array}$ & $\begin{array}{l}\text { By the teacher's design of an activity with the purpose of work- } \\
\text { ing on storytelling and on the concept of algorithms (sequences } \\
\text { and procedures). }\end{array}$ \\
\hline Tangible Environment & $\begin{array}{l}\text { By providing a wooden robot with plastic programming blocks } \\
\text { and a rug where the story takes place, besides a photocopy of } \\
\text { the rug and pens for the children to think and play with possible } \\
\text { routes/solutions. }\end{array}$ \\
\hline Evaluation & $\begin{array}{l}\text { By analyzing a form where the children wrote down their } \\
\text { ideas, possible solutions, drafts and simulations, besides ob- } \\
\text { serving the children's participation in the activities. At the } \\
\text { end of each activity, the use of the Self-Assessment Manikin } \\
\text { (SAM) [Bradley and Lang 1994]. }\end{array}$ \\
\hline
\end{tabular}

Table 2. Thinking, Tinkering, and Reflecting with educators and children.

\begin{tabular}{l|l|l}
\hline \hline Moment & Educators & Children \\
\hline \hline Thinking & $\begin{array}{l}\text { Elaboration and simulation of } \\
\text { workshop. }\end{array}$ & $\begin{array}{l}\text { Elaboration and simulation of pos- } \\
\text { sible ideas for the resolution of the } \\
\text { challenge. }\end{array}$ \\
\hline Tinkering & $\begin{array}{l}\text { Conduction of the workshop with } \\
\text { children, evaluation, and on the fly } \\
\text { corrections of the routes. }\end{array}$ & $\begin{array}{l}\text { Programming the robot and experi- } \\
\text { menting possible solutions in order } \\
\text { to solve the challenge. }\end{array}$ \\
\hline Reflecting & $\begin{array}{l}\text { Reflection on the workshop, goal } \\
\text { achievements, and new insights for } \\
\text { new workshop, based on observa- } \\
\text { tions and evaluation tools used. }\end{array}$ & $\begin{array}{l}\text { Discussion of the final solution, } \\
\text { mentioning the difficulties faced } \\
\text { and how they were overcome. }\end{array}$ \\
\hline
\end{tabular}

tinkering with the blocks and the robot to understand what was wrong, devise, and implement new solutions, leading them to understand possible mistakes during the initial planned solution.

In relation to the dimensions of Pleasure and Arousal, as evaluated by the educators, $67 \%$ experienced a positive affective response in the first workshop rising to $100 \%$ in the second. In relation to Dominance, during first workshop, $17 \%$ presented a positive 
VIII Congresso Brasileiro de Informática na Educação (CBIE 2019)

Anais do XXV Workshop de Informática na Escola (WIE 2019)

affective response, $66 \%$ neutral, and $17 \%$ a negative response. In the second workshop, $25 \%$ presented a neutral response and $75 \%$ presented a negative response for Dominance. We attributed this high percentage of negative responses for the Dominance dimension, to the use of procedures, a much more difficult (abstract) concept. One way to overcome this, is to have more time for the educators to tinker with the tangible artifact, in order to gain confidence on their relation with it. Regarding the children, we obtained $100 \%$ of positive responses in the Pleasure dimension, both in the first and second workshops. In the dimension of Arousal, we observed $75 \%$ positive affective responses in the first one, increasing to $100 \%$ in the second workshop. In the Dominance dimension, we observed negative affective response by $42 \%$ of the children in the first workshop, reducing it to $17 \%$ in the second workshop. Here, again we can associate it with more time of tinkering with the artifacts the children have.

As shown on Table 1, all the elements of the proposed framework were covered in the design of the activities. This finding shows that the educators reached a good practice of the principles of constructionism and creative learning in their work with children and technology. Moreover, we can point out that the proposed framework and workflow were effective in supporting their approach to the new technology and to the design and experimentation of a learning environment scenario with their students.

\section{Conclusion}

The use of methodologies for designing activities that aim to develop skills associated with computational thinking allied with the use of tangible artifacts can foster the largescale adoption of more effective learning/teaching procedures, like those presented by constructionism and creative learning. In this work, we proposed a framework to support educators in the design of educational environment scenarios, based on constructionism and on creative learning principles.

We explored the use of the proposed framework in the context of an educational space where we conducted two workshops with educators and two with fifteen 8 to 11 years old students. The workshops with the educators aimed at their design of activities to develop computational thinking skills through problem-solving, using a tangible artifact. The children's workshops were conducted with activities designed by the educators, based on the proposed framework and on the three-moments workflow - thinking, tinkering, and reflecting, that are key to the construction of knowledge. The findings showed the effectiveness of this framework, supporting and organizing the design of activities by the educators and the experimentation with their students. Although some preliminary evaluation of their affective response to the practices with the proposed learning scenario are encouraging, a specification of a protocol to guide a comprehensive evaluation of the framework by educators is still necessary. Finally, we point out that the role of the educator in the process of appropriating themselves of new technology to use with children is crucial. Moreover, they should create strategies to foster the engagement of all and the reflection on the results achieved, the problems faced, and the solutions encountered. At this point, encouraging students to be conscious about the three-moment workflow when they are solving problems can be valuable.

Further research involves to observe and support educators in their process of designing educational environment scenarios, enriched with contemporary technology, 
VIII Congresso Brasileiro de Informática na Educação (CBIE 2019)

Anais do XXV Workshop de Informática na Escola (WIE 2019)

aiming at other knowledge domains (e.g., Math or History), and considering other CTrelated concepts, and with children of different ages. Additionally, we plan to develop a platform for educators, based on the proposed framework, with the possibility of sharing technology, scenario designs, experiences, and evaluations.

\section{Acknowledges}

This research is supported by São Paulo Research Foundation (FAPESP), grant \#2015/16528-0. Additional support was provided by the National Council of Technological and Scientific Development (CNPq) under grants \#306272/2017-2 and \#307560/20163 and by the Coordenação de Aperfeiçoamento de Pessoal de Nível Superior - Brasil (CAPES) - Finance Code 001.

\section{References}

Ackermann, E. (1995). Construction and transference of meaning through form. Constructivism in education, pages 341-354.

Bradley, M. M. and Lang, P. J. (1994). Measuring emotion: the self-assessment manikin and the semantic differential. Journal of behavior therapy and experimental psychiatry, 25(1):49-59.

Horn, M. S., Solovey, E. T., Crouser, R. J., and Jacob, R. J. (2009). Comparing the use of tangible and graphical programming languages for informal science education. In Proceedings of the SIGCHI Conference on Human Factors in Computing Systems, CHI '09, pages 975-984, New York, NY, USA. ACM.

Ishii, H. and Ullmer, B. (1997). Tangible bits: Towards seamless interfaces between people, bits and atoms. In Proceedings of the ACM SIGCHI Conference on Human Factors in Computing Systems, CHI '97, pages 234-241, New York, NY, USA. ACM.

Liao, Y.-K. C. and Bright, G. W. (1991). Effects of computer programming on cognitive outcomes: A meta-analysis. Journal of Educational Computing Research, 7(3):251268.

Papert, S. (1980). Mindstorms: Children, computers, and powerful ideas. Basic Books.

Papert, S. (1993). The Children's Machine: Rethinking School in the Age of the Computer. Basic Books, Inc., New York, NY, USA.

Papert, S. and Harel, I. (1991). Situating constructionism. Constructionism, 36(2):1-11.

Resnick, M. and Robinson, K. (2017). Lifelong kindergarten: Cultivating creativity through projects, passion, peers, and play. MIT Press.

Resnick, M. and Rosenbaum, E. (2013). Designing for tinkerability. Design, make, play: Growing the next generation of STEM innovators, pages 163-181.

Wing, J. M. (2006). Computational thinking. Communications of the ACM, 49(3):33-35.

Zuckerman, O., Arida, S., and Resnick, M. (2005). Extending tangible interfaces for education: Digital montessori-inspired manipulatives. In Proceedings of the SIGCHI Conference on Human Factors in Computing Systems, CHI '05, pages 859-868, New York, NY, USA. ACM. 